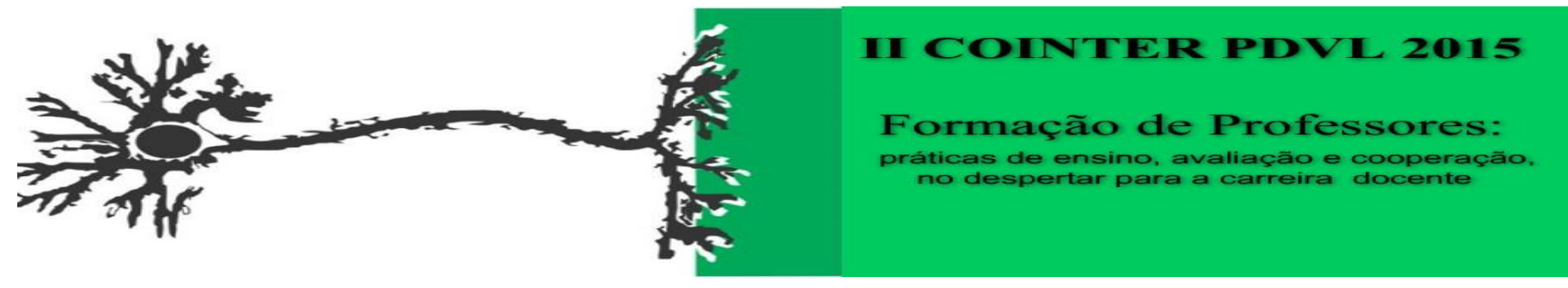

\title{
OS SERVIÇOS DE LIMPEZA URBANA COMO INSTRUMENTOS DE GESTÃO AMBIENTAL: ESTUDO DE CASO NO MUNICÍPIO DE PETROLINA-
} PE.

\author{
Apresentação: Comunicação Oral \\ SOLANGE MARIA DANTAS GOMES - solange.gomes@ifsertao-pe.edu.br \\ BERTRAND SAMPAIO ALENCAR; CELSO SALES FRANCA; VIVIANE DE SOUZA
}

\begin{abstract}
RESUMO
Este trabalho tem como objetivo avaliar a gestão dos serviços de limpeza pública oferecidos à população no município de Petrolina por meio da análise de indicadores. Visando atingir os objetivos deste trabalho, num primeiro momento, foi realizada uma pesquisa bibliográfica, inclusive consultas das principais legislações e normas aplicadas à gestão de resíduos sólidos e saneamento básico. Foram aplicados formulários com questões fechadas e realizadas observações in loco nos diversos setores de atuação das empresas contratadas para a prestação dos serviços de limpeza pública. O estudo identificou falhas na operação e no processo de monitoramento e avaliação destes serviços, às quais estão associadas a um planejamento insipiente da gestão destes serviços. A falta de integração entre os diversos órgãos e atores envolvidos na realização das ações previstas contribui para agravar a situação. Verificou-se que cada responsável se ocupa das atividades que considera essenciais, resultando no descontrole e insatisfação dos usuários. A pesquisa identifica ao final a necessidade de medidas essenciais na integração das ações existentes e, sobretudo, na obtenção de melhores resultados. Propõe-se como recomendações que, os profissionais do setor e os gestores municipais possam contar com mais um instrumento de apoio à tomada de decisão sobre os serviços de limpeza pública que envolve a coleta e o transporte, a limpeza de vias e logradouros (varrição, raspagem, poda, limpeza de canais) e a coleta seletiva, de forma a cumprir as metas da Política Nacional de Resíduos Sólidos e da Política Nacional de Saneamento Básico, atendendo as exigências do arcabouço legal vigente.
\end{abstract}

Palavras chave: Limpeza Pública, Resíduos Sólidos, Planejamento de Serviços Públicos. 


\section{INTRODUÇÃO}

Os resíduos produzidos, nos municípios se tornaram uma problemática, não só para a própria população, como também para os gestores federais, estaduais e municipais, que devido ao grande volume de produção, a escassez de espaços físicos, a falta de comprometimento com políticas públicas, dentre outros, para a destinação adequada, acabam gerando consequências na saúde da população, na estética das cidades e na degradação do meio ambiente.

A variável ambiental tem, portanto, sido um dos principais eixos na definição de políticas com o intuito de adequar as demandas sociais aos limites naturais especialmente na atualidade. No Brasil não tem sido diferente. Entretanto, isso não significa necessariamente que os interesses desse contexto se sobreponham aos interesses econômicos. Isso se evidencia de forma clara na demora e na escassez da definição de mecanismos para fazer valer as diretrizes presentes na legislação vigente em seus diversos campos, seja: na pesca, na agricultura, na destinação de resíduos perigosos, etc.

Essa preocupação tem expressa importância quando se refere à legislação brasileira que após 21 anos em tramitação, aprovou em agosto de 2010 a Política Nacional de Resíduos Sólidos, instituída em 2 de agosto de 2010 como a Lei Federal № 12.305 (BRASIL, 2010). No Brasil, A Política Nacional de Resíduos Sólidos (PNRS) estabelece as diretrizes e metas para a área de gestão e gerenciamento dos resíduos sólidos no país e cria instrumentos para que os entes federados, o setor produtivo e a sociedade civil se articulem no sentido de garantir o descarte adequado destes resíduos, envolvendo a gestão pública local no processo de responsabilidade pelas ações que efetivamente implicarão no seu sucesso ou insucesso.

Tratar a temática de resíduos sólidos é, portanto, de significativa importância, principalmente quando se observa que a administração pública de diversos países vem elaborando políticas de gestão para resíduos sólidos com base na eficiência técnica dos serviços e no equilíbrio de gastos públicos com esses serviços. Essa modalidade implica em intensificar a gestão dos resíduos de forma que a gestão tradicional, caracterizada pela coleta nos centros urbanos e o seu descarte nas periferias destes, seja substituída pela gestão 
moderna, que possui como estratégia principal a eficiência na prestação dos serviços de coleta e tratamento através do uso de tecnologias.

Sem querer adentrar em minúcias administrativas, sabe-se que boa parte da prestação de serviços públicos carece, entre outros quesitos, de planejamento e avaliação precisos para o aperfeiçoamento da técnica e melhoria da qualidade. Sem isso se torna impraticável os desdobramentos das gestões que venham a depender dessa dinâmica mal construída ao longo de um processo que muitas vezes parte de quem administra o recurso e chega até o final sem o estabelecimento de meios, metas, resultados satisfatórios: quantificáveis e para uma boa governança.

Uma ferramenta fundamental para o êxito na efetiva realização de princípios e objetivos da Política Nacional de Resíduos Sólidos - PNRS, é a elaboração de um Plano Municipal de Gestão de Resíduos Sólidos - requisito fundamental para que os municípios obtenham recursos federais destinados a esse fim. Portanto, pensar os municípios sem a devida estruturação e planejamento quanto ao tratamento e destinação de resíduos, é submetê-los a um futuro incerto no trato das questões ambientais. Apesar disso, gestores não conseguem aliar os valores ambientais à sustentabilidade do desenvolvimento local.

Além das políticas dirigidas especificamente e em atenção ao exigido pela Lei 12.305/2010, chama a atenção a situação dos catadores. Esses, embora sejam atores principais para a implantação de ações relacionadas a esta política pública, permanecem em sua maioria como trabalhadores informais, normalmente sem ocupação profissional definida, residindo em bairros periféricos nos centros urbanos, vivem à margem da sociedade, são beneficiados precariamente pelos serviços de saúde, não contam com a disponibilidade da maior parte dos serviços urbanos e residem em moradias inadequadas, continuando assim invisíveis à gestão pública, à população, haja vista que não estão inseridos na cadeia produtiva da reciclagem, pois comercializam o produto da catação por preços módicos e quando vinculados a alguma organização pública recebem remuneração irrisória pelos seus serviços, insuficientes até mesmo para a sua sobrevivência. 
Considera-se a relevância deste estudo, pela oportunidade de poder assumir esse novo desafio teórico e prático, ao acreditar na possibilidade da construção de um novo projeto de sociedade, que valorize ao mesmo tempo a condição humana e a gestão ecologicamente prudente dos recursos naturais.

A opção por um estudo de caso justifica-se também, pelo fato de possibilitar a coleta de evidências por meio de diferentes fontes, entre as quais se destacam entrevistas, levantamento em campo, além da pesquisa bibliográfica que ao mesmo tempo permite comparar esta, com outras experiências existentes. No nosso plano de coleta de evidências foram utilizadas essas fontes, por vezes concomitantemente, por vezes de forma isolada.

Torna-se assim necessário analisar as políticas promovidas pelo poder público municipal, estadual e federal, tendo em conta não só a sua complexidade como o cruzamento de interesses e estratégias dos diversos atores, o que implica considerar as diferentes respostas e apreciações em torno da implementação das políticas estatais.

Entre os motivos que levaram à escolha deste estudo está a preocupação em investigar de que maneira o município trata a política de limpeza pública urbana, especialmente quanto à coleta do lixo, varrição, poda e limpeza de canais e quais os parâmetros adotados para a aferição de resultados, a realidade local e o índice de satisfação dessas comunidades, visando influir na estruturação desses processos e na melhoria desta realidade.

\section{FUNDAMENTAÇÃO TEÓRICA}

Com o início do processo de civilização humana o homem passou a produzir para promover seu próprio bem estar alguns utensílios como vasilhames de cerâmica, instrumentos utilizados no plantio, roupas e começou também a desenvolver hábitos como construção de moradias, criação de animais, cultivo de alimentos, além de se fixar de modo permanente em um local por ele escolhido. Neste contexto, a partir da formação destas primeiras aglomerações humanas, a produção de resíduos foi aumentando e passando a 
se tornar um problema uma vez que the trazia consequências e algumas destas relacionadas a doenças.

As preocupações da sociedade com o lixo, entretanto, não são tão recentes e remontam à Idade Antiga (3.000 a.C. a 476 a.C.) com o surgimento de grandes cidades e os problemas relacionados aos resíduos. A ausência de melhoramentos com o lixo e os excrementos humanos levou ao surgimento de pragas e de doenças (ALENCAR, 2010).

Numa breve leitura histórica, algumas considerações acerca das principais aglomerações ou comunidades na Idade Antiga, conforme descrito por Eigenheer (2009), questões importantes suscitam a realidade atual, tais como: a cobrança de taxa pelo uso de serviços, a realização da limpeza de canais realizada por prisioneiros de guerra e apenados.

Na Idade Antiga, merece destaque a condição do Império Romano que na sua decadência leva consigo muitas de suas conquistas sanitárias, especialmente no que se refere a Roma, trazendo consequências funestas e a incidência de endemias e uma drástica redução de sua população que somente depois de 1250 teve o estabelecimento de normas para a destinação do lixo e cuidados com o abastecimento de água.

Na Idade Média, a utilização de fossas acabou por trazer problemas de contaminação aos poços e fontes d'agua e consequências à saúde da população. Foi a partir do século XIV, que passou a ocorrer o sepultamento dos corpos próximos às igrejas e consequentemente aos aglomerados urbanos, 0 que acabava ainda por contaminar as fontes de água.

Após esse período, teve início um processo de maior cuidado com o sepultamento e os cemitérios passaram a se localizar um pouco mais distantes das cidades, visando a redução desse problema. Nessa época era bastante comum o uso de fezes humanas para a adubação do solo. Inclusive, no Brasil, que se serviu desse modelo até o início do século XIX.

As mudanças ocorridas no final do século XVIII e início do século XIX modificaram o cenário promovendo um grande e acelerado êxodo rural, triplicando o número da população nos centros urbanos da Inglaterra e demais países onde aconteceu a Revolução Industrial. 
As mudanças substanciais na limpeza urbana, inclusive com a aplicação de algumas tecnologias, somente tiveram início na segunda metade do século XIX, pois as graves implicações sanitárias ocorridas obrigavam a adoção de medidas com essa finalidade, inclusive, em relação à possibilidade de contaminação das áreas mais nobres da cidade com as mazelas dos bairros operários, como a peste negra. Foi possivelmente a partir desse período que a humanidade passou a distinguir entre lixo (resíduos sólidos) e águas servidas (urina, fezes, etc.) e estas passaram a ser coletadas separadamente através do esgotamento sanitário. $O$ avanço da ciência e uma nova visão da saúde pública especialmente em relação aos dejetos e a qualidade da água a ser consumida naquela época, fizeram surgir uma nova concepção atrelada ao saneamento.

Nota-se que no século XX houve muitos avanços no tocante a questão dos resíduos sólidos, levando-se em conta que remover e tratar lixo e outros resíduos sólidos e esgoto numa cultura urbano-industrial são indispensáveis, contudo, isso não significa que a situação da limpeza urbana, mesmo nos países desenvolvidos esteja definitivamente equacionada, pois em boa parte, os sistemas ainda são inadequados.

$\mathrm{Na}$ cidade de Petrolina a preocupação com o acúmulo de resíduos somente começou a se tornar mais presente a partir dos anos 70 quando 0 município possuía uma população de 54.238 habitantes. Na primeira metade da década de 80 , Petrolina teve um aumento considerável da população urbana, passando, portanto, por uma significativa transformação do seu espaço agrário, que através dos investimentos do Estado, aprimorou a sua atividade agrícola. A cidade começou a receber um maior número de migrantes, impulsionados pela agricultura irrigada e teve como um dos reflexos imediatos do fluxo migratório o déficit habitacional. As condições de higiene na cidade de Petrolina que nessa década eram bastante precárias com esgotos que corriam a céu aberto e o depósito de lixo em terrenos periféricos da cidade.

O primeiro Código de Postura do Município foi instituído através da Lei №10, de 16 de maio de 1983. Esse Código se baseava essencialmente no controle da higiene, ordem, segurança e sossego público e do funcionamento das atividades comerciais, industriais e de prestação de serviços e esse 
momento foi caracterizado com uma atuação bastante eficiente de fiscalização e bons resultados.

Observa-se que de modo similar ao que se apresenta no cenário brasileiro após a realização da Eco 92, somente a partir da década de 900 município demonstra efetivamente preocupação em criar dispositivos legais que visem a garantia da preservação do meio ambiente, seja através do Código de Posturas, da Lei Orgânica, do Fundo Municipal de Meio ambiente ou ainda de uma Agência Municipal de Meio Ambiente.

Sabemos que os serviços públicos envolvem uma grande diversidade de ações. No tocante à limpeza, a logística da gestão de resíduos sólidos envolve: coleta, transporte, acondicionamento e destinação final e figura como um dos serviços prestados pela administração pública municipal.

Os desafios são, portanto, na mesma proporção e grandeza dos problemas. Os esforços de modernização geram produtos inovadores em alguns setores da gestão pública, mas as dificuldades se fazem presentes em todas as estruturas, emperrando processos e fazendo-os ineficientes e consequentemente pouco produtivos.

Transformar burocracias em organismos empreendedores, eficientes e produtivos, tem uma estreita relação com um recente fenômeno mundial: o ceticismo do cidadão sobre a capacidade do Estado em administrar a sociedade e satisfazer suas crescentes e complexas necessidades sociais.

A expectativa de serviços de boa qualidade acaba então se confrontando com a execução de serviços de baixa qualidade, gerando 0 descrédito geral na administração pública. Nesse contexto de deterioração e descrédito, a responsabilidade na gestão de serviços públicos, na direção de um melhor aproveitamento do orçamento público é fundamental. No entanto, recai-se em outros problemas estruturais: o planejamento e o controle de custos.

O manejo de resíduos sólidos no país ainda é uma situação preocupante, principalmente quanto à disposição final, uma vez que apenas $39,53 \%$ dos 5.570 utilizam os aterros como disposição final para os resíduos. Os outros $60,47 \%$ continuam utilizando os lixões como destinação final para os 
resíduos produzidos nas cidades, de acordo com dados fornecidos pelo Ministério do Meio Ambiente (2014). Isso demonstra a necessidade de mudança de conceitos e forma de tratar o assunto, visando o alcance de melhores resultados no manejo de resíduos sólidos urbanos.

Uma das principais questões que se relacionam com os resíduos, é que estes percorrem um longo caminho que compreende: geração, descarte, coleta, tratamento e disposição final. Esse processo envolve diversos atores e um tratamento meramente técnico não ocasiona resultados satisfatórios. Requer a implantação de um modelo de gestão dos resíduos sólidos. Exemplo disso é a instituição da Política Nacional de Resíduos Sólidos no ano de 2010.

Outro ponto importante a ser considerado é o significativo aumento na produção per capita de resíduos e ao processo de crescimento das cidades que vem se intensificando, bem como a necessidade de investimentos na aquisição de equipamentos, treinamento, capacitação, controle e custeio do sistema.

Os desafios que travam a evolução da situação atual quanto à questão dos resíduos, se dão normalmente pela ausência de estratégias e planejamento, pois na gestão de resíduos a vontade política da administração deve ser aliada de ações concretas, às quais não funcionam paralelamente.

Alencar (2009) menciona que entre as prioridades da Gestão Integrada de Resíduos sólidos estão a redução dos fluxos de resíduos, a reutilização, e a reciclagem de materiais, a conservação ambiental, a participação popular, o controle social e a sustentabilidade. A gestão integrada contempla aspectos financeiros, administrativos, sociais, ambientais e técnico-operacionais, entretanto, significa bem mais que o gerenciamento dos aspectos técnicooperacionais do serviço, extrapola os limites da administração pública, tem no aspecto social um ponto forte e envolve a participação do setor público (primeiro setor) o setor privado (segundo setor) e as organizações não governamentais (terceiro setor), e estes se desenvolvem desde o pensar do modelo de planejamento, a estratégia de atuação, forma de execução e de controles. 
Esse conceito deve ter como pano de fundo os resíduos sólidos e suas implicações e entre elas estão: a definição de ações, estratégias e procedimentos que busquem o consumo responsável, a minimização da geração de resíduos e a promoção do gerenciamento adequado e sustentável com a efetiva participação da sociedade, no entanto, a Inter cooperação dos atores sociais exerce papel fundamental no êxito dos resultados.

A relação das dimensões que envolvem o desenvolvimento sustentável seja: ecológica, ambiental, demográfica, cultural, social, política, institucional, ética, legal, e o atendimento a estas é um processo bastante complexo na prática. Se por vezes são atendidos alguns desses requisitos, outros deixam de ser atendidos e percebe-se que tratar a questão dos resíduos com vistas à sustentabilidade é algo que precisa de bastantes ações práticas para sua garantia, especialmente ao se tratar sobre a coleta seletiva, à qual visa suprir com qualidade as necessidades locais, busca estabelecer uma melhor relação custo-benefício e ser aperfeiçoado em todos os segmentos e esferas.

No tocante a questão de serviços públicos, mais especificamente, de limpeza urbana, paira no senso comum da população a ideia de que este é um serviço gratuito, e, portanto, deve ser garantido pelo poder público e por isso não costuma ser observado os critérios mínimos de exigência na prestação desses serviços.

\section{METODOLOGIA}

A metodologia utilizada nesta pesquisa trata da sistematização das informações coletadas nas 5 (cinco) empresas contratadas envolvidas nos serviços de limpeza urbana em Petrolina, das tecnologias a serem empregadas e ainda na implantação de um sistema de monitoramento e avaliação dos serviços.

Quanto à proposta final deste trabalho, o estudo trata-se do método qualitativo, pois esta pesquisa consistiu em fazer o diagnóstico da situação atual da gestão dos serviços de limpeza pública na cidade de Petrolina e propor diretrizes para a implantação de um novo gerenciamento. 


\section{RESULTADOS E DISCUSSÕES}

Levando-se em conta que os municípios têm como função inerente a prestação de serviços que podem ser executados de forma direta pelo Governo Municipal ou indireta por delegação de terceiros, há de se dispensar a devida atenção para que estes sejam prestados de forma igualitária e indistintamente a toda comunidade, atendendo necessidades e aspirações dos cidadãos, devendo, para tanto, atingir um limite mínimo de eficiência, não se admitindo solução de continuidade.

No Brasil, a maior parte dos municípios deveria realizar o serviço de limpeza urbana com as receitas advindas da cobrança da Taxa de Limpeza Pública (TLP) incluída no IPTU. No entanto, são as demais receitas oriundas de transferências intergovernamentais, a exemplo do ICMS (estadual) e FPM (federal) que remuneram estes serviços.

Os serviços de limpeza urbana no município de Petrolina são realizados por empresas terceirizadas e gerenciados pela Secretaria de Infraestrutura que tem como área de atuação a limpeza urbana, manutenção de praças e limpeza de canais, além de cuidar da pavimentação e da iluminação pública. Além dessa Secretaria, o município criou por meio da Lei no 2.354, de 30/03/11, a Agência Municipal do Meio Ambiente - AMMA, que tem entre outras competências o desenvolvimento de ações que visem à adequada destinação dos resíduos sólidos gerados no território do município.

No município de Petrolina os serviços de limpeza urbana são os seguintes: coleta e transporte, limpeza de vias e logradouros (varrição, poda, pintura de meio-fio e raspagem), limpeza de canais e serviços cemiteriais (efetuados pelos coveiros). São custeados pelo poder público municipal o qual por meio de processo licitatório contrata empresas e terceiriza os serviços.

Observa-se que muitos incentivos são oferecidos pelo governo federal com a finalidade de estimular ações públicas relacionadas ao meio ambiente, no entanto, não é suficiente equacionar problemas de custos dos serviços. $O$ compromisso municipal deverá ser direcionado para soluções e tecnologias compatíveis com o cenário local, promover a redução de resíduos em suas fontes geradoras através da educação ambiental permanente e ações voltadas 
à coleta seletiva, devidamente estruturada com remuneração justa para os catadores.

Todas essas ações devem ser pactuadas com a sociedade por meio de campanhas educativas, corresponsabilização de autorias e estabelecimento de metas de redução da disposição de resíduos.

\section{CONSIDERAÇÕES FINAIS}

Este trabalho buscou entender como é realizada a gestão dos resíduos sólidos urbanos, englobando os serviços de limpeza urbana no município de Petrolina e como se apresenta no cenário atual de aplicação da Política Nacional de Resíduos Sólidos.

Com a pesquisa bibliográfica, análise de dados secundários e a realização de um estudo de caso procurou-se obter as respostas para essas questões e a partir daí recomendar um plano de ação conjunta, especialmente quanto ao que se constatou, qual sejam um fracionamento e uma compartimentalização das ações hoje existentes, bem como a falta de monitoramento das ações por parte do poder público.

O município de Petrolina possui um diferencial em relação aos municípios vizinhos, seja pela economia local ou principalmente pelo fato de abrigar algumas instituições de ensino técnico e superior. Esse cenário atrai um vasto corpo técnico e de profissionais e estudantes que podem atuar no sentido de modificar as políticas municipais por meio de atuação como sociedade civil e por meio de projetos de pesquisa e extensão como algum já existente, entretanto é reconhecido que esse é um esforço que depreende das instituições e do poder público um grande e significativo esforço para o cumprimento das políticas ambientais em vigor.

Outro ponto a ser considerado é que algumas das indicações foram avaliadas a partir da situação observada no momento das visitas e ou estudos de campo, não se apoiando em dados. Esse é um cenário no qual, os dados constantes nos contratos, não se tornaram conhecidos inviabilizando assim um aprofundamento das questões. 
Alguns itens que o município enumera como grandes ganhos na verdade ainda não se encontram completos em sua plenitude como por exemplo a construção e o funcionamento de um aterro sanitário, pois sem a devida separação dos materiais, e uma sistemática de coleta seletiva, isso não representa ganhos significativos para o município, levando-se em conta os custos envolvidos nesses processos e os benefícios ao meio ambiente caso sejam implantados.

Outro ponto que merece especial destaque é falta de informação e preparo técnico dos gestores e equipe especialmente quando ações de intervenção envolvem educação ambiental, mobilização social e inclusão social e isso demonstra de forma clara a necessidade de melhoria desse cenário.

Por fim e com base no que foi analisado, é fundamental a gestão e gerenciamento integrado de resíduos sólidos e as medidas necessárias à integração das ações existentes para a obtenção de melhores resultados. Com a maximização desses esforços, haveria melhores condições de contribuir na destinação final ambientalmente adequado dos resíduos sólidos e a melhoria dos serviços de limpeza urbana como um todo, uma vez que, além dos serviços de coleta avaliados de modo razoável pela população, os demais serviços que envolvem a limpeza pública pouco representam em termos de qualidade e garantia de sustentabilidade ambiental. O planejamento do sistema deveria prevê, portanto, um escopo claro, especificando a qualidade dos serviços a serem prestados e estruturas necessárias. Além disso, há necessidade de realizar uma leitura sistêmica da cadeia de serviços que envolvem a limpeza urbana, elaborar estrategicamente processos com vistas à redução de ineficiência, custos, e melhoria de resultados nos setores envolvidos. 


\section{REFERÊNCIAS}

ALENCAR, Bertrand Sampaio. Gerenciamento Integrado de Resíduos Sólidos: Uma abordagem estratégica e operacional. Bainema:2009. Recife

BRASIL, Secretaria Nacional de Saneamento Ambiental Sistema Nacional de Informações sobre Saneamento: diagnóstico do manejo de resíduos sólidos urbanos - 2010. - Brasília: MCIDADES.SNSA, 2012.

Secretaria Nacional de Saneamento Ambiental. Dadosdo Brasil para a primeira avaliação regional 2002 dos serviços de manejo de resíduos sólidos municipais nos países da América latina e Caribe. Brasília: OPAS/OMS, 2004.

, Lei n. 12305, de 3 de agosto de 2010. Institui a Política Nacional de Resíduos Sólidos; altera a Lei no 9.605, de 12 de fevereiro de 1998; e dá outras providências. Diário Oficial [da]República Federativa do Brasil, Bras'lia,DF, 3 ago.2010. Disponível em:<http://www.planalto.gov.br/ccivil_03/_ato20072010/2010/lei/l12305.htm

, Lei n. 11445, 5 de janeiro de 2007. Estabelece diretrizes nacionais para o saneamento básico; altera as Leis $\mathrm{n}^{\text {os }} 6.766$, de 19 de dezembro de 1979, 8.036, de 11 de maio de 1990, 8.666, de 21 de junho de 1993, 8.987, de 13 de fevereiro de 1995; revoga a Lei no6.528, de 11 de maio de 1978; e dá outras providências. Diário Oficial [da]República Federativa do Brasil, Brasília,DF, $\quad 5 \quad$ jan. 2010.2 Disponível em:<http://www.planalto.gov.br/ccivil 03/ ato2007-2010/2007/lei/114445.htm

Decreto n. 7404, 23 de dezembro de 2010. Regulamenta a Lei no 12.305, de 2 de agosto de 2010, que institui a Política Nacional de Resíduos Sólidos, cria o Comitê Interministerial da Política Nacional de Resíduos Sólidos e o Comitê Orientador para a Implantação dos Sistemas de Logística Reversa, e dá outras providências.. Diário Oficial [da] República Federativa do Brasil, Brasília,DF, 23dez. 2010.2 Disponível em:<http://www.planalto.gov.br/ccivil 03/ ato20072010/2010/Decreto/D7404.htm

.Diagnóstico do manejo de resíduos sólidos urbanos-2004. Programa de Modernização do Setor Saneamento:.Brasília: Ministério das Cidades, 2006. 
SILVA FILHO, Carlos Roberto Vieira da Gestão de resíduos sólidos: o que diz a lei. Carlos Roberto da Silva Filho, Fabrício Dourado Soler. - São Paulo: Trevisan Editora Universitária, 2012.

STUART, I et al. Effective Case Research in Operations Management: A Process Perspective, in: Journal of Operations Management, v. 20, n.5, p. 419-433, 2002.

ABRELPE. Panorama dos Resíduos Sólidos no Brasil 2012 Associação Brasileira de Empresas de Limpeza pública e Resíduos Especiais . 2012-

ITEP. Plano Estadual de Gestão Consorciada e Integrada de Resíduos Sólidos de Pernambuco. Relatório Técnico dos Levantamentos em Campo das Características dos Resíduos Sólidos dos Municípios de Petrolina, Afrânio, Bodocó, Salgueiro, Mirandiba, Carnaubeira da Penha, Triunfo, Custódia, Arcoverde, Bom Conselho, Estado de Pernambuco. Anexo B, v.4. 2011.

MESQUITA Júnior, José Maria de. Gestão integrada de Resíduos Sólidos. Coordenação de Karina Segala. Rio de Janeiro: IBAM, 2007. 